\title{
El inframundo y los mensajes moralizantes en la iconografía de la Reforma neerlandesa El caso de Van Swanenburg
}

Paulina de los Ángeles Beltrán Carrara

Universidad de Glasgow

The Underworld and Moralizing Messages in the Iconography of the Dutch Reformation

The Van Swanenburg Case

Recepción: 12 de enero de 2021

Aceptación: 3 de junio de 2021 


\title{
Resumen
}

Mediante una comparación iconográfica se propone que el pintor neerlandés Jacob Isaacsz van Swanenburg (1571-1638) evoca en sus paisajes del inframundo un modelo visual que deriva del taller de Brueghel; se distinguen las semejanzas y diferencias en tres obras de Van Swanenburg y una de Jan Brueghel el Joven. Se argumenta que la recuperación de la Eneida de Virgilio, así como las inquietudes religiosas de la Reforma y Contrarreforma introdujeron una serie de elementos simbólicos que Van Swanenburg utiliza para construir alegorías morales que apelan a distintas inquietudes religiosas sobre la muerte y la justicia.

\section{Palabras clave}

Eneida, Brueghel, boca del infierno, siete pecados capitales, alegorías de justicia

\begin{abstract}
Through an iconographic comparison it is proposed that the Dutch painter Jacob Isaacsz van Swanenburg (1571-1638) evokes in his landscapes of the underworld a visual model derived from Brueghel's workshop. The article highlights the similarities and differences in three works by Van Swanenburg and one by Jan Brueghel the Younger. It is argued that the recovery of Virgil's Aeneid, as well as the religious concerns of the Reformation and Counter-Reformation introduced a series of symbolic elements that Van Swanenburg uses to construct moral allegories appealing to different religious concerns about death and justice.
\end{abstract}

\section{Keywords}

Aeneid, Brueghel, hellmouth, seven deadly sins, allegories of justice 
ESTE ARTíCULO BUSCA APROXIMARNOS A LAS CONDICIONES EN LAS QUE JACOB ISAACSZ van Swanenburg formuló un estándar de representación del inframundo. Nacido en 1571, hijo de Isaac Van Swanenburg, artista y alcalde de la ciudad de Leiden, Jacob estudió en Italia y estableció su oficio en 1617. ${ }^{1}$ Hasta el momento no se conocen estudios enfocados al artista, cuyo rol ha sido reducido al del primer maestro de Rembrandt. Se cuestiona a qué se debe su interés en pintar el inframundo conforme a la Eneida y qué componentes simbólicos de la representación del inframundo católico continuaron durante la Reforma. Se realiza también un análisis iconográfico ${ }^{2}$ de tres obras de su producción que representan el inframundo: dos de ellas son interpretaciones de la Eneida de Virgilio y la tercera, una visión apocalíptica del Juicio Final. Así, se consideran dos premisas: 1) que el lenguaje visual presente en la obra de Van Swanenburg deriva directamente del taller de Brueghel; y 2) que Van Swanenburg adapta su obra a las predilecciones estéticas de la Reforma y la Contrarreforma.

La obra de Van Swanenburg se sitúa en relación a factores culturales, sociales y económicos dentro del cisma de la Reforma protestante. De forma secundaria, se reconstruyen las circunstancias de producción de su obra en función a los intereses pictóricos de la época, ausentes en la historiografía del pintor. Al comparar estas imágenes se busca resaltar las analogías temáticas, así como la versatilidad del artista para satisfacer discursos aparentemente opuestos. Por consiguiente, se argumenta que Van Swanenburg utiliza textos que refieren al infierno, como la Eneida y el "libro de las Revelaciones", para construir un imaginario que concentre inquietudes tanto católicas como protestantes sobre la muerte y la distinción entre justos y pecadores.

\section{Comparativa iconográfica}

Analicemos primero Eneas llevado por la Sibila al Infierno (fig. 1). En el poema épico de Virgilio, Eneas sobrevive a la guerra de Troya y después

1 Haak, The Golden Age, 222-225.

2 Panofsky, Studies in Iconology, 3-31. 
de un largo peregrinar, desembarca en Italia. Van Swanenburg retoma el sexto libro, donde Eneas entra al averno con ayuda de la Sibila Cumana para buscar a su padre Anquises. Una vez dentro, encuentra a su padre, quien le muestra su progenie, el Imperio Romano. Este óleo fue concebido en Leiden en el siglo xvII, periodo de prosperidad para el mercado textil que propició el auge de la pintura. ${ }^{3}$

Una ciudad en llamas, el cielo cubierto de humo, Neptuno y Venus sentados en una carroza dorada sobre una nube, rodeados por sirenas. Los corceles se funden con las nubes; abajo, el inframundo. Un soldado apunta al mástil torcido de un barco indicando un cambio inesperado en su travesía. Su postura es valerosa, vestido con túnica y armadura, su cabeza protegida con una gálea de cresta carmesí. Una joven lo acompaña, ambos de pie sobre una masa de cuerpos en una nave fantasmagórica. A su derecha, Caronte sostiene el remo de su barca, descansando un pie sobre la espalda de un hombre. Las almas desnudas luchan por aferrarse, incapaces de subir a la embarcación. Seres repugnantes pueblan el inframundo. A la izquierda, una figura alada lleva a un hombre y a una mujer para ser arrojados a un cazo. Un personaje alado atormenta las almas con una lanza. Múltiples criaturas ejercen la flagelación y tormentos, una bestia con cara de pájaro observa mientras los mortales son arrastrados y quemados.

En la parte inferior derecha, Eneas contempla la entrada al inframundo. El héroe carga su espada sobre el hombro derecho, sujetando la empuñadura; al cinto, una borla rosácea asegura la vaina de una daga. Camina firme, acompañado de la Sibila Cumana, con su largo y rubio cabello trenzado en una corona ornamentada, usa un vestido largo sobre una túnica lazada a la cintura y extiende sus brazos mostrando el sitio a Eneas; a su derecha está Caronte arrodillado con la cabeza baja. El sexto canto de la epopeya es representado mediante la repetición y reubicación de las figuras de Eneas y la sibila, que refleja el paso del tiempo.

\footnotetext{
${ }^{3}$ Haak, The Golden Age, 222-225.
} 
Nierika 21 - Año 11 - enero-junio de 2022

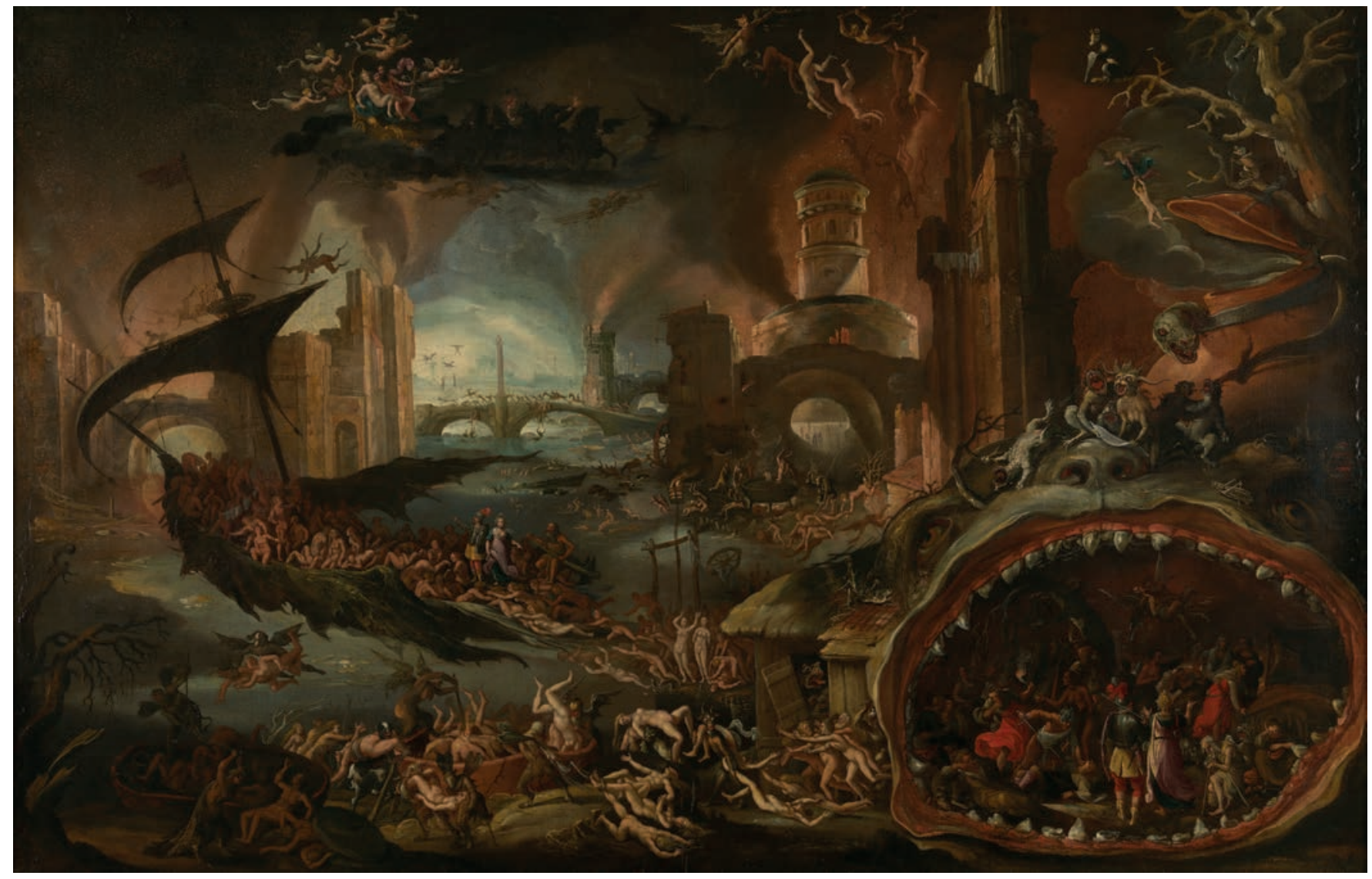

Figura 1. Atribuido a Jacob Isaacsz van Swanenburg, Eneas Ilevado por la sibila al infierno, siglo xVII, óleo sobre madera, Royal Museums of Fine Arts of Belgium, Bruselas, inv. 10241, fotografía de J. Geleyns. Disponible en https://www.fine-arts-museum.be/fr/ la-collection/jacob-isaacsz-van-swanenburgh-attribue-a-enee-conduit-par-la-sibylle-aux-enfers (consultado el 6 de abril de 2020). 
La boca del infierno es representada como las fauces de una bestia siniestra de colmillos putrefactos. Dentro, una oscuridad abismal induce a lo desconocido. Una anciana yace en el umbral, curiosa por ver a los recién llegados. A la izquierda de Eneas, un soldado herido se dispone a empalar a un hombre. Una gorgona vestida de rojo muerde una manzana mientras levanta una antorcha. En la oscuridad, figuras desnudas con cuencas vacías denotan angustia. Sobre la boca de la bestia, secuaces demoniacos de aspecto desagradable riñen entre sí, criaturas híbridas, ejecutores del inframundo. Uno de ellos, con largas extremidades y garras, detiene su caída aferrándose a una rama. Tres más parecen sostener una hoja de papel mientras profieren alaridos. La entrada al infierno humea como un horno, su chimenea es custodiada por una bestia reptilforme.

Para interpretar la visión de Van Swanenburg de la Boca del Infierno debemos recurrir a otra obra del maestro. Una evaluación comparativa indica que el artista comunica valores protestantes mediante alteraciones en la composición. Inframundo con el barco de Caronte (fig. 2) describe el mismo pasaje de la Eneida. Propiedad del Museo Lakenhal, la composición es considerablemente similar a la de Colecciones Reales (fig. 1). Destaca la ausencia de Eneas y la sibila, mientras que en el primer ejemplo ambos personajes claramente se encuentran dentro de la Boca del Infierno. En esta versión, el carruaje de Neptuno y Venus aparece a la izquierda y la diosa, con el brazo derecho levantado, señala al cielo. Una de las figuras que acompañan el carruaje sostiene una antorcha en referencia al origen del fuego. En el extremo derecho del encuadre resaltan tres figuras humanas en cuclillas sobre la fumarola del averno; en la punta, un hombre barbado vestido de negro porta una gorguera blanca, su ropa es propia del siglo XVII. A su derecha, un hombre encapuchado suena una campana; tras ellos, una monja con hábito negro y cofia blanca une sus manos en oración. Debido a los detalles fisonómicos de estas figuras, podemos sugerir que son verdaderos personajes históricos, quizá los comitentes u otras figuras destacadas de la sociedad de Leiden.

La intención moralizante es mucho más explícita en Inframundo con el barco de Caronte (fig. 2) en comparación con Eneas llevado por la sibila 
al infierno (fig. 1). El sufrimiento de las almas advierte las consecuencias del exceso. Los pecados se representan encarnados individualmente con una iconografía convencional. Como describe la cédula del museo: "La mujer reclinada como personificación de la pereza, una pareja de amor como el de la lujuria, una mujer que expresa su lengua como del mal hablar. Una mujer con una bolsa representa la avaricia, una dama vestida con un espejo representa la vanidad y un hombre codicioso representa la intemperancia". ${ }^{4}$

En los paisajes infernales de Van Swanenburg es clara la influencia de Jan Brueghel el Joven, quien a su vez se inspiró en Jan Brueghel el Viejo para pintar este tipo de escenarios. ${ }^{5}$ En el taller de Brueghel las escenas proverbiales y paisajes decorativos fueron prolíficos en Amberes. Como herencia del estilo de su padre y a veces firmando en su nombre, Brueghel el Joven carecía de un estilo propio. ${ }^{6}$

Contrario a la epopeya, en la pintura de Brueghel el héroe es quien guía a la Sibila (fig. 3), lo que implica que el pintor añadió su propia interpretación a la representación. En el texto, Eneas llega al inframundo en busca de virtud: ${ }^{7}$ para transmitir visualmente esa cualidad se enfatizó la valentía del personaje con una pose viril. Sin embargo, obvió los tormentos de las almas. Mientras que en las imágenes de Van Swanenburg (figs. 1 y 2) los castigos y verdugos están individualizados, la población del inframundo de Brueghel se convierte en una masa de cuerpos en posturas imposibles. Las almas de Van Swanenburg carecen de marcadores de sexo o estatus, mientras que Brueghel los diferencia. En el grupo ubicado a la extrema derecha, criaturas anfibias conducen a mujeres suntuosamente ataviadas, una descubre sus enaguas rojas y otra resalta en dorado. Fundamentalmente, la reiteración del tema en ambos pintores demuestra un constante interés por recuperar la literatura clásica y sus moralejas.

${ }^{4}$ Cfr. Museo Lakenhal, Underworld with Charon's Boat.

5 Liedtke, "Addenda to 'Flemish Paintings'...", 101-120.

6 Cfr. Getty, "Jan Breughel the Younger".

7 Wilson, Virgil in the Renaissance, 145-190. 


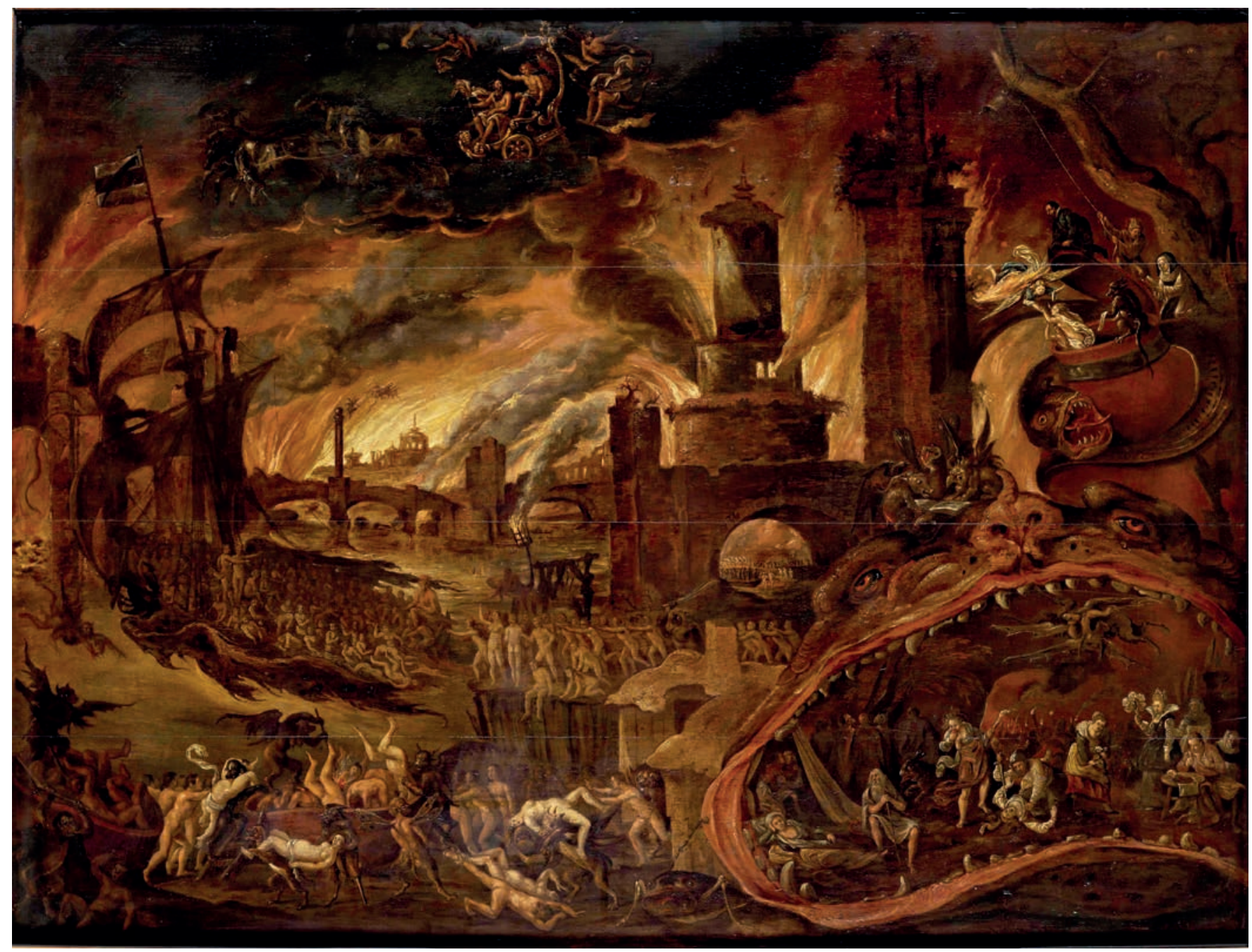

Figura 2. Jacob Isaacsz van Swanenburg, Inframundo con el barco de Caronte, ca.1620, óleo sobre madera, Lakenhal Museum, Leiden, inv. S251. Reproducido bajo licencia de CC0 1.0 Universal (CC0 1.0). Disponible en https://www.lakenhal.nl/en/ collection/s-251 (consultado el 6 de abril de 2020). 
Nierika 21 - Año 11 - enero-junio de 2022

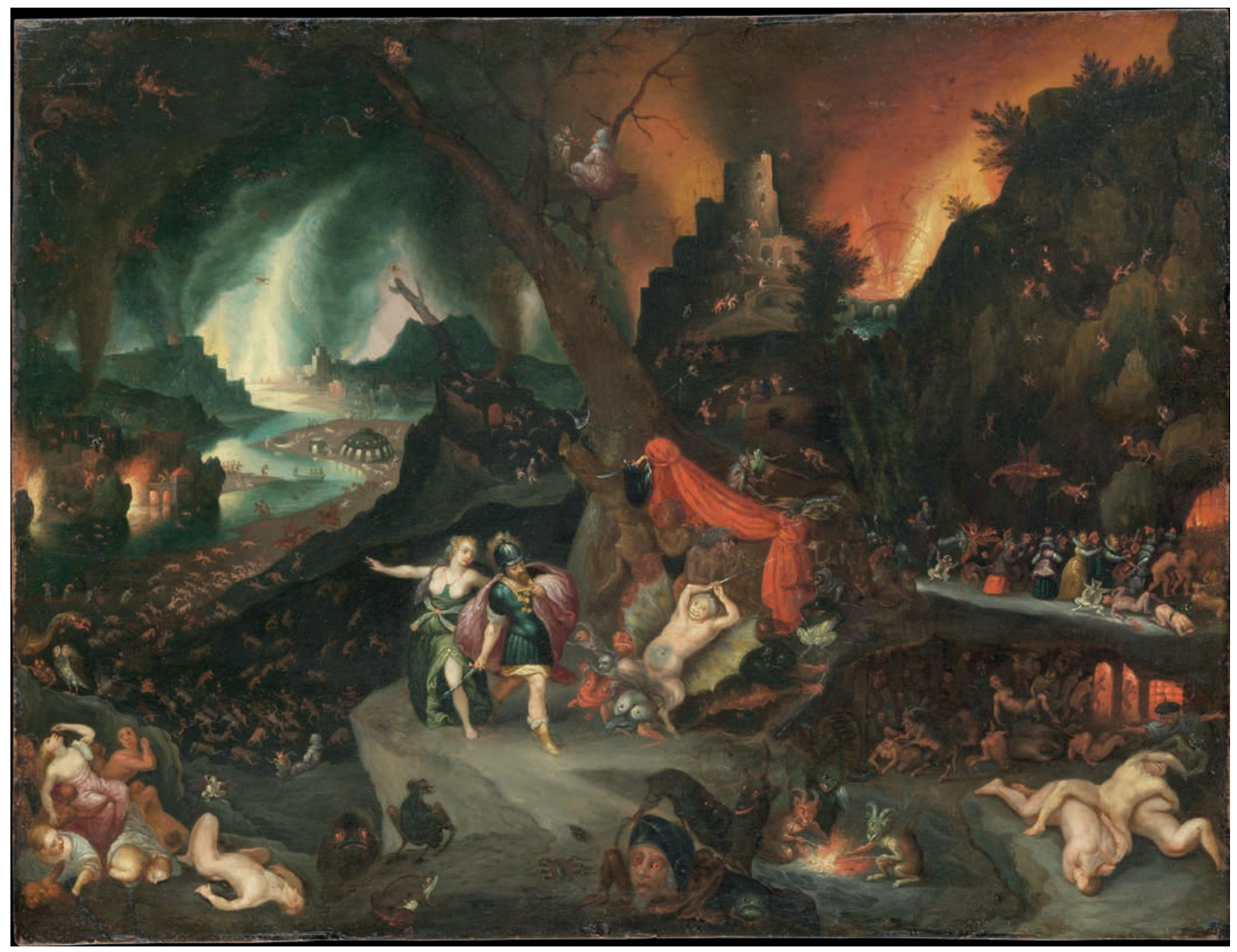

Figura 3. Jan Brueghel el Joven, Eneas y la sibila en el inframundo, ca. 1630, óleo sobre cobre, Metropolitan Museum of Art, Nueva York. Reproducido bajo licencia de Creative Commons: CC0 1.0 Universal (CC0 1.0). Disponible en https://www.metmuseum.org/art/ collection/search/435813 (consultado el 6 de abril de 2020). 
El juicio final y los siete pecados capitales (fig. 4) de Van Swanenburg comparte el mismo núcleo iconográfico. Las escenas del "juicio final" ganaron popularidad entre 1560 y $1590 .{ }^{8}$ Sobreviven múltiples obras relativas al tema de Crispijn van den Broeck, Jacob de Backer y Frans Floris. El rostro de la bestia imita al de Eneas llevado por la sibila al infierno (fig. 1). El pintor recurre en repetidas ocasiones a las alegorías del pecado, similares a Inframundo con el barco de Caronte (fig. 2). Van Swanenburg persistió en representar los cuerpos indistintamente para aludir a la humanidad, en vez de a un grupo en particular. Una diferencia importante entre las tres obras de Van Swanenburg (figs. 1, 2 y 4) es que en esta última disminuyen las figuras demoniacas y su relevancia para la narrativa, como las tres que aparecen en la esquina inferior izquierda. Otra diferencia es que, si bien se nos presenta un barquero, éste no es reconocible como Caronte ya que no pertenece al imaginario católico.

Los ejemplos anteriores constatan que la representación del infierno según Brueghel influenció la obra de Van Swanenburg, quien a su vez, hizo

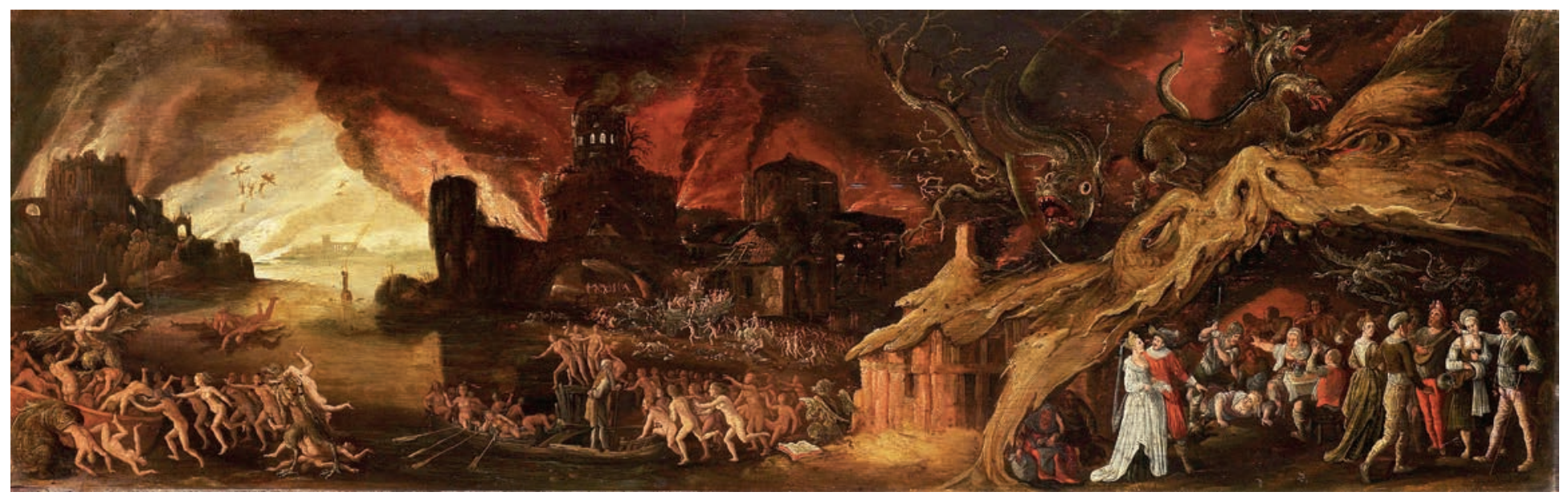

Figura 4. Jacob Isaacsz van Swanenburg, El juicio final y los siete pecados capitales, 1600-1638, óleo sobre madera, Rijksmuseum, Ámsterdam. Disponible en https://www.rijksmuseum.nl/en/collection/SK-A-730 (consultado el 6 de abril de 2020).

8 De Clippel, "Smashing Images", 51-73. 
pequeños pero significativos cambios que añaden nuevas lecturas a su obra. El averno era un tema frecuente en el taller de su familia desde 1582, cuando el ayuntamiento de Leiden encargó a su padre una serie de cinco cuadros para el Tribunal de Justicia. La serie incluyó temas como el juicio de Cambises, el juicio de Salomón y el juicio final, presentados constantemente "como exempla". ${ }^{9}$ Es muy probable que, a los 11 años de edad, en su etapa formativa, Van Swanenburg tuviera su primer acercamiento con este repertorio iconográfico. Willem, su hermano menor, realizó una serie de grabados sobre el juicio final y otras alegorías de la justicia entre 1606 y 1607, algunos se conservan en Los Angeles County Museum of Art (LACMA) y en la National Gallery of Art de Washington. ${ }^{10}$ Sin embargo, la atmósfera sombría, las torres, fumarolas y árboles torcidos que Van Swanenburg incorpora en sus paisajes infernales tienen precedente en la dinastía Brueghel. A partir de las similitudes iconográficas en Eneas llevado por la sibila (fig. 1), Inframundo con el barco de Caronte (fig. 2) y El juicio final (fig. 4), queda manifiesta la habilidad de Van Swanenburg para copiar modelos de composición con el fin de facilitar su reproducción. La recurrencia del tema le permitió cambiar detalles formales menores, ahorrando tiempo y asegurando ingresos adicionales. ${ }^{11}$

\section{Relación con el entorno}

Las tres obras de Van Swanenburg abren una ventana a los intereses pictóricos de su tiempo. Las tensiones ocasionadas durante la Reforma y la Contrarreforma definieron su inclinación por representar el inframundo de la Eneida. En Países Bajos, la Reforma protestante exigió una reevaluación del arte religioso. Se advirtió por medio de imágenes contra la compra de indulgencias para obtener la salvación espiritual, lo que exacerbó las preocupaciones de la clase media por observar una vida de templanza y

\footnotetext{
9 Van der Velden, "Cambyses for Example", 9.

10 Cfr. National Gallery of Art, "Willem Swanenburgh".

11 Las copias tenían una gran demanda por lo que los artistas solían conservar los originales como "modelo" y las copias de menor calidad resultaban más accesibles. De Marchi y Van Miegroet, "Art, Value, and Market Practices...", 456.
} 
mesura aún en la emergente bonanza económica. ${ }^{12} \mathrm{Al}$ reconocer el mensaje protestante, las alegorías morales impulsaron la introspección. ${ }^{13}$ Con la Reforma se destruyeron innumerables obras de arte sacro; según el estudio econométrico de Etro y Stepanova,${ }^{14}$ el interés por la pintura de paisajes creció, mientras que las obras figurativas perdieron participación en el mercado y disminuyó el patrocinio para comisiones religiosas.

A partir de la Reforma, los pensamientos y actitudes sobre el más allá se representaron utilizando textos clásicos. Indicación de ello es la recuperación de Ovidio, efecto de la publicación de 1484 y la ilustración de la adaptación moralizada de Metamorfosis. ${ }^{15}$ De manera similar, el libro Schilder-Boek de Karel van Mander sobre la práctica del arte resultó crucial para los maestros holandeses del siglo xvı. Avalado por textos griegos y romanos, Van Mander busca la moralización de la imagen..$^{16}$ Asimismo, las escenas mitológicas estaban cargadas de significantes morales; las gorgonas y arpías simbolizan luchas colectivas y los demonios femeninos son física y moralmente grotescos, con emociones desmesuradas. ${ }^{17}$

Con el cambio de pensamiento, cambiaron las convenciones iconográficas. La crisis en la comprensión de la teología afectó las reglas del decoro, como la ostentación de la desnudez condenada en los decretos tridentinos; pese a ello, un grupo nominal de artistas pintó desnudos para comisiones de uso público. ${ }^{18}$ Se fusionaron motivos cristianos y grecorromanos para el desarrollo de la iconografía del infierno, donde se castigan los pecados capitales mediante penas y tormentos específicos, según la teología medieval. ${ }^{19}$ En los tratados pictóricos como el de Francisco Pacheco, se instaba a representar los demonios mediante acciones, no mediante una

\footnotetext{
12 Gibson, "Artists and Rederijkers...", 443.

13 Freedberg y De Vries, Art in History, 175-192.

14 Etro y Stepanova, "Entry of Painters...", 329.

15 Huges, Heaven and Hell in Western Art, 195.

16 Melion, Shaping the Netherlandish Canon, 36.

17 West, Women in Vergil's Aeneid, 127-132.

18 De Clippel, "Smashing Images", 51-73.

19 Giorgi, Angels and Demons in Art, 68-78.
} 
forma particular. Si se pintaba a Satanás, Pacheco propone continuar la tradición de representarlo como un dragón, criatura inmortal y "por naturaleza horrible". ${ }^{20}$

La migración dentro de los Países Bajos resultó en la expansión de la audiencia y el aumento en la demanda de pintura de género con moralejas menos rigurosas. Los funcionarios del gobierno comisionaron temas mitológicos por razones cívicas ${ }^{21}$ y la élite para disfrute privado. ${ }^{22}$ Entre los retóricos se debatió sobre la política romana como la descrita en la Eneida, la difusión del humanismo italiano, la mitología y se propuso el refuerzo de los valores en la poesía, el teatro y la literatura. ${ }^{23}$ Destacan Cornelis van Ghistele, quien escribió la obra Eneas y Dido entre 1551 y $1552^{24}$ y Johan de Witt que en 1654 consideró la República romana como modelo a seguir en la política holandesa. ${ }^{25}$

A la fecha, dos obras de Van Swanenburg y otras 24 asociadas a su familia permanecen en Leiden. ${ }^{26} \mathrm{~A}$ diferencia de Van Swanenburg, quien se especializó en alegorías, el gremio de Leiden desarrolló la pintura de género. ${ }^{27}$ Durante el primer cuarto del siglo XVII, la pintura de historia alcanzó un precio de más de 47.60 florines y la pintura de género $27.79 .{ }^{28} \mathrm{El}$ costo de la obra dependía de los materiales, horas de trabajo y la reputación del artista; tarifas que la corte y las autoridades políticas estaban dispuestas a costear. ${ }^{29}$ Tanto pintores como marchantes debían registrarse en el gremio de San Lucas, pagar impuestos y seguir las regulaciones que protegían a los artistas locales, impidiendo las subastas, loterías y la promoción de artistas de otras ciudades. ${ }^{30}$

20 Pacheco, On Christian Iconography, 108.

${ }^{21}$ Van der Velden, "Cambyses for Example", 7.

22 De Clippel, "Smashing Images", 51-73.

${ }^{23}$ Freedberg y de Vries, Art in History, 185.

${ }^{24}$ Gibson, "Artists and Rederijkers...", 430.

25 Israel, "The Uses of Myth...", 14.

${ }^{26}$ Cfr. Museo Lakenhal, Underworld with Charon's Boat.

27 Etro y Stepanova, "Entry of Painters...", 327.

28 De Marchi y Van Miegroet, "Art, Value, and Market...", 460.

${ }^{29}$ Boers-Goosens, "Prices...", 60.

30 Montias, "Art Dealers...", 247. 


\section{Análisis y reflexión}

Los paisajes infernales de Van Swanenburg deben interpretarse a la luz del cambio religioso de la Reforma, que plantea el temor de Dios como motivación para una vida piadosa. Escritores y poetas como Joost van den Vondel afirmaron que los mitos concebidos a partir de la sabiduría de los antiguos podían conducir a conceptos más allá del hombre. ${ }^{31}$ Desde el discurso calvinista (fe predominante en los Países Bajos del Norte) el arte acerca al cielo, sitio que conjuga sentimientos de atracción y temor, de manera que el miedo y la devoción son uno mismo en la experiencia religiosa.

Van Swanenburg recupera algunos componentes simbólicos del catolicismo en sus paisajes del inframundo, como los pecados con sus castigos correspondientes y la ciudad en llamas, una posible referencia a la ira de Dios sobre Sodoma y Gomorra (Génesis 19:24) o a la visión del infierno según San Antonio de Padua. ${ }^{32}$ Van Swanenburg utilizó el plano de fondo como referencia espacial en sus paisajes infernales. La apertura de la boca del infierno es un recurso narrativo que combina múltiples episodios adyacentes a la escena principal. El uso de Doorsiens ${ }^{33}$ permite una transición entre el fondo y la posición de los personajes para destacarlos en la escena. ${ }^{34}$ Aunque estos temas eran presentados en un contexto secular, la doctrina cristiana continuó resonando por medio de mensajes moralizantes. ${ }^{35}$ Las imágenes sombrías de Van Swanenburg lo han convertido en uno de los favoritos de los visitantes del Museo de Antiguos Maestros, perteneciente al conjunto de Museos Reales de Bellas Artes de Bélgica. ${ }^{36}$ Desafortunadamente, no se encontraron fuentes exclusivas sobre su obra y sólo se cuenta con una sucinta biografía. En comparación con maestros holande-

\footnotetext{
31 Bussels, "Theories of the Sublime...", 887.

32 Giorgi, Angels and Demons in Art, 68-78.

${ }^{33}$ Dispositivo pictórico utilizado en Países Bajos para representar múltiples planos en una escena como referencia para el posicionamiento espacial y la percepción de profundidad y/o distancia. Hollander, An Entrance..., 16.

${ }^{34}$ Hollander, An Entrance..., 16.

35 Van der Velden, "Cambyses for Example", 10.

${ }^{36}$ Google Arts and Culture, "Royal Museums of Fine Arts of Belgium".
} 
ses como Rembrandt y Vermeer, las obras de Van Swanenburg no han sido estudiadas a profundidad, la escasa información sobre el artista es accesible al público únicamente mediante los registros de obra de los museos, que raramente establecen su procedencia. Por consiguiente, la presente investigación encontró un hueco historiográfico y sugiere futuros estudios sobre el maestro.

Además de los escasos indicios sobre el artista, no resulta sencillo situarlo en relación a sus contemporáneos, porque historiográficamente se encuentra en el umbral entre los primitivos flamencos ${ }^{37}$ y el barroco holandés ${ }^{38}$ también llamado "siglo de oro neerlandés". Siguiendo las pautas de Wölfflin, ${ }^{39}$ podríamos clasificar a Van Swanenburg como barroco en su composición dinámica, dramatización, representación de multitudes y fervor religioso, más aún en sus emociones violentas; sin embargo, ya entrado el siglo XVII Van Swanenburg continúa pintando escenas religiosas con la iconografía de sus predecesores, por lo que no comulga con el barroco holandés que dio paso al realismo de la pintura de género. Es muy clara la diferencia con el estilo de Rembrandt (1606-1669), indudable representante del Siglo de Oro. Sin pertenecer del todo a una corriente artística, parece apropiado que Van Swanenburg se encuentre en un "limbo" historiográfico como el de sus paisajes.

En conclusión, Van Swanenburg ajustó los modelos iconográficos de su taller para responder a los nuevos intereses temáticos que resultaron de la Reforma. Adecuó un pasaje de la Eneida de manera que fuera identificable el mensaje moralizante. Desarrolló un modelo propio de alegoría que incorpora motivos cristianos y grecorromanos que, a diferencia de Brueghel, su predecesor, va más allá de recuperar la literatura clásica, puesto que

\footnotetext{
37 Panofsky (1953) y Friedländer (1981) determinaron que el periodo de los primitivos flamencos comienza en 1425 y comprende artistas "de Van Eyck a Brueghel". Friedländer, From Van Eyck to Bruegel, 135.

${ }^{38}$ La pintura del Siglo de Oro se caracteriza por su realismo; resaltaron la cotidianidad, el nacionalismo y los valores cívicos, su sentido didáctico no era manifiesto. Westerman, "After Iconography and Iconoclasm", 361.

39 Wölfflin, Renacimiento y Barroco, 13-25.
} 
revela los miedos y preocupaciones de una sociedad cambiante. A su vez, pintar el inframundo implica la comprensión de textos bíblicos para elaborar un escenario que transmita sentimientos de contrición y esperanza de salvación.

Como tema en el arte, la interpretación calvinista de la Eneida fue recibida con fascinación y temor, ${ }^{40}$ sentimientos que Van Swanenburg enfatizó en sus estremecedores paisajes del inframundo. En su modelo de la boca del infierno, el artista evidenció sus propias inquietudes religiosas, como el principio calvinista del temor de Dios. Podemos deducir que Van Swanenburg vio en la Eneida una estrategia de comunicación que podía alinearse indirectamente tanto al cristianismo como al protestantismo. En las obras Eneas llevado por la sibila e Inframundo con el barco de Caronte (figs. 1 y 2) se demuestra la relación entre arte, mito y poesía como un nexo a lo divino, interés de los retóricos de su tiempo. Su iconografía responde a la maduración estética del gusto por las escenas del infierno derivadas de la Edad Media. El tema forma parte de un género pictórico bien recibido, ya que las similitudes iconográficas se repiten en múltiples composiciones de la época. Van Swanenburg privilegia la iconografía del cristianismo en sus alegorías, de la cual recobra la simbología de los pecados capitales, demonios y tormentos, como en Inframundo con el barco de Caronte (fig. 2). La confluencia de dogmas cristianos, calvinistas y grecorromanos confieren a Van Swanenburg una perspectiva única del trasmundo, que escenificada en la pintura, es presagio y sentencia del infame.

\section{Bibliografía}

De Marchi, Neil y Hans J. van Miegroet. "Art, Value, and Market Practices in the Netherlands in the Seventeenth Century". The Art Bulletin 76, núm. 3 (1994), 451-464.

40 West, Women in Vergil's Aeneid, 127-132. 
Freedberg, David y Jan de Vries. Art in History: History in Art: Studies in Seventeenth-Century Dutch Culture. Santa Mónica: Getty Center for the History of Art and the Humanities, 1991.

Friedländer, Max J. From Van Eyck To Bruegel. Oxford: Phaidon, 1981.

Giorgi, Rosa. Angels and Demons in Art. Los Ángeles: J. Paul Getty Museum, 2005.

Haak, Bob. The Golden Age: Dutch Painters of the Seventeenth Century. Nueva York: Harry N. Abrams, 1984.

Hollander, Martha. An Entrance for the Eyes: Space and Meaning in Seventeenth-Century Dutch Art. Berkeley: University of California Press, 2002.

Huges, Robert. Heaven and Hell in Western Art. Londres: Weidenfeld \& Nicolson, 1968.

Melion, Walter. Shaping the Netherlandish Canon. Chicago: University of Chicago Press, 1991.

Pacheco, Francisco. On Christian Iconography: Selections from the Art of Painting (1649). Filadelfia: Saint Joseph's University Press, 2017.

Panofsky, Erwin. Studies in Iconology: Humanistic Themes in the Art of Renaissanse. Londres: Routledge, 2018.

West, Grace S. Women in Vergil's Aeneid. Londres: University Microfilms International, 1980.

Wilson Okamura, David S. Virgil in the Renaissance. Cambridge y Nueva York: Cambridge University Press, 2010.

Recursos electrónicos

Ainsworth, Maryan W. "Early Netherlandish Painting". En Heilbrunn Timeline of Art History. Nueva York: The Metropolitan Museum of Art, 2009. Disponible en http://www.metmuseum.org/toah/hd/enet/hd_enet.html (consultado el 4 de junio de 2021).

Boers-Goosens, Marion. "Prices of Northern Netherlandish Paintings in the Seventeenth Century”. En A. Golahny, M. M. Mochizuki y L. Vergara (eds.). In his Milieu, Essays on Netherlandish Art in Memory of John 
Michael Montias. Ámsterdam: Amsterdam University Press, 2006, 5972. Disponible en https://www.jstor.org/stable/j.ctt45kdcx.9 (consultado el 16 de marzo de 2020).

Bussels, Stijn. "Theories of the Sublime in the Dutch Golden Age: Franciscus Junius, Joost van den Vondel and Petrus Wittewrongel". History of European Ideas, vol. 42, núm. 7 (mayo de 2016): 882-892. Dol: 10.1080/ 01916599.2016.1161532. Disponible en https://www.tandfonline.com/ doi/full/10.1080/01916599.2016.1161532 (consultado el 17 de marzo de 2020).

De Clippel, Karolien. "Smashing Images. The Antwerp Nude between 1563 and 1585". En Art After Iconoclasm: Painting in the Netherlands between 1566 and 1585, editado por Koenraad Jonekheere y Ruben Suykerbuyk: 51-74. Turnhout: Brepols, 2012. Disponible en http://www.columbia.edu/ cu/arthistory/faculty/Freedberg/Art-after-Iconoclasm.pdf (consultado el 17 de marzo de 2021).

Etro, Federico y Elena Stepanova. "Entry of Painters in the Amsterdam Market of the Golden Age". Journal of Evolutionary Economics (2016): 317-348. Disponible en https://www.researchgate.net/publication/ 2995 67719 (consultado el 17 de marzo de 2020).

Getty. "Jan Breughel the Younger". Disponible en http://www.getty.edu/art/ collection/artists/754/jan-brueghel-the-younger-flemish-1601-1678 (consultado el 19 de marzo de 2020).

Gibson, Walter S. "Artists and Rederijkers in the Age of Bruegel". The Art Bulletin 63, núm. 3 (septiembre de 1981): 426-446. Disponible en https:// www.jstor.org/stable/3050144 (consultado el 15 de marzo de 2020).

Google Arts and Culture. "Royal Museums of Fine Arts of Belgium". Disponible en https://artsandculture.google.com/partner/royal-museums-of-fine-arts-of-belgium (consultado el 17 de marzo de 2020).

Israel, Jonathan I. "The Uses of Myth and History in the Ideological Politics of the Dutch Golden Age". En Jane Fenoulhet y Lesley Gilbert (eds.). Narratives of Low Countries History and Culture: Reframing the Past. Londres: UCL Press, 2016, 9-17. Disponible en https://www.jstor.org/ stable/j.ctt1hd18bd.5 (consultado el 15 de marzo de 2020).

Lempertz. "Jacob Isaacsz van Swanenburg, attributed to - The Temptation of Saint Anthony”. Disponible en https://www.lempertz.com/en/catalogues/ 
lot/1067-1/1248-jacob-isaacsz-van-swanenburg-attributed-to.html (consultado el 16 de marzo de 2020).

Liedtke, Walter. Addenda to "Flemish Paintings in the Metropolitan Museum of Art". Metropolitan Museum Journal 27 (1992): 101-120. Disponible en https://www.jstor.org/stable/1512938 (consultado el 16 de marzo de 2020).

Montias, John Michael. "Art Dealers in the Seventeenth-Century Netherlands in Simiolus". Netherlands Quarterly for the History of Art 18, núm. 4, (1988): 244-256. Disponible en https://www.jstor.org/stable/3780702 (consultado el 16 de marzo de 2020).

Museo Lakenhal. Underworld with Charon's Boat. Disponible en https:// www.lakenhal.nl/en/collection/s-251 (consultado el 16 de marzo, 2020).

National Gallery of Art (Washington). "Willem Swanenburgh". Disponible en https://www.nga.gov/collection/artist-info.6311.html (consultado el 17 de marzo de 2020).

Royal Museums of Fine Arts of Belgium. "The collection". Disponible en https://www.fine-arts-museum.be/nl/de-collectie/ (consultado el 16 de marzo de 2020).

VAds (Visual Arts Data Service). "The Holy Family". Disponible en https:// vads.ac.uk/ (consultado el 16 de marzo de 2020).

Van der Velden, Hugo. "Cambyses for Example: The Origins and Function of an exemplum iustitiae in Netherlandish Art of the Fifteenth, Sixteenth and Seventeenth Centuries". Simiolus: Netherlands Quarterly for the History of Art 23, núm. 1, (1995): 5-62. Disponible en https://www.jstor. org/stable/3780781 (consultado el 10 de marzo de 2020).

Westerman, Mariët. "After Iconography and Iconoclasm: Current Research in Netherlandish Art, 1566-1700". The Art Bulletin 84, núm. 2 (junio de 2002): 351-372. Disponible en https://www.jstor.org/stable/3177273 (consultado el 16 de marzo de 2020).

Wölfflin, Heinrich. Renacimiento y Barroco. Barcelona: Paidós, 1986. Disponible en https://historiandotodos.files.wordpress.com/2014/04/14333834 9-wolfflin-heinrich-renacimiento-y-barroco.pdf (consultado el 4 de junio de 2021). 


\section{Paulina de los Ángeles Beltrán Carrara}

Actualmente cursa una maestría en la Universidad de Glasgow. Licenciada en Historia del Arte por la Universidad Iberoamericana. En 2019 colaboró en la digitalización de las colecciones del Museo Soumaya y su lanzamiento en la plataforma Google Arts and Culture. Ha presentado trabajos de investigación en ponencias para las universidades de Bristol y Nottingham. 